Marqués Ibáñez, Ana.

Profesora Ayudante Doctor, Universidad de La Laguna, Departamento de Bellas Artes.

amarquez@ull.edu.es

Peña Sánchez, Noemí

Profesora Ayudante Doctor, Universidad de Valladolid, Departamento de Didáctica de la Expresión Musical, Plástica y Corporal.

noemi.pena@mpc.uva.es

\title{
Arte y contextos. De la emoción a la creación.
}

\author{
TIPO DE TRABAJO \\ Comunicación. \\ PALABRAS CLAVE \\ Arte, contexto, identidad, percepción social, integración.
}

KEY WORDS

Artwork, context, identity, social perception, integration.

RESUMEN

Esta comunicación hace una reflexión sobre el planteamiento del arte como una necesidad expresiva y comunicativa del artista. El contexto se presenta como ese marco de referencia en el que el artista se sitúa e inspira para realizar su obra. Ese territorio se configura como un espacio de vivencias, sentimientos, sucesos que conmueven al individuo. Los conflictos, la represión, la inmigración, la pobreza, entre otras problemáticas, provocan un cambio de perspectiva de la realidad que vemos. En el caso de ciertos artistas, este contexto es punto de partida clave para establecer un diálogo a través del arte.

\begin{abstract}
Langer (1966) define obra de arte como "una forma expresiva creada para nuestra percepción a través de los sentidos o la imaginación, y lo que expresa es sentimiento humano"(p.23). Esta idea refleja como la percepción y la creación de una obra mantienen una estrecha vinculación con las emociones que suscita una determinada obra. Para el artista, ese contexto íntimo marcado por sentimientos de dolor, de alivio, de pérdida provocan la necesidad de expresar esa problemática. Para el espectador, el arte es capaz de provocar "sentimientos" sobre aquello que percibimos, aunque lo representado, sea ajeno a nuestro contexto real.
\end{abstract}

Presentamos una revisión de propuestas artísticas enfocadas precisamente a la necesidad del artista de dar visibilidad a problemáticas sociales y culturales y que ciertamente provoquen una respuesta en el espectador. Planteamos así dar visibilidad a obras marcadas por una preocupación social y definir modos de acercamiento a través del arte de estas problemáticas. En este sentido consideramos que el estudio de las obras debe estar íntimamente ligado a tres conceptos: obra, artista y contexto.

\section{ABSTRACT}

We reflect on art as an expression on the artist's need for communication. The context is introduced as the framework in which the artist stands and that contributes to inspire the artist to produce works of art. Territory is configured as a space in which experiences, feelings and other events that move and inspire the artist take place. Conflicts, repression, immigration, poverty, are among the negative realities that can cause a shift in the perspective from which the artist sees reality. For some artists, this broader context is the key starting point for establishing and creating a dialogue through art. 
Langer (1966) defines artwork as "a form of expression that communicates human feelings created for our perception through the senses or the use of imagination" (p.23). This idea reflects how perceptions and the creation of an artwork have a close connection with the emotions aroused by a particular work. For the artist, her intimate context is marked by feelings that could be for instance of pain, relief or loss and that motivate the artist to express those feelings via the work of art. For the viewer, the art is able to produce "feelings" about what we perceive, even though the object represented by the artwork might be alien or more distant to the viewer daily context or reality.

We present a review of artistic proposals aimed precisely at the artist's need to give visibility to social and cultural issues that are able to arouse a response in the viewer. In this way, we propose to give visibility to works marked by a social concern. These are also works of art that suggest ways for the viewer to get closer to these social concerns. In this regard we believe that the study of these artworks must be undertaken simultaneously considering three closely linked concepts: work, artist and context.

\section{INTRODUCCIÓN}

Frecuentemente el arte pone énfasis en cuestiones sociales, políticas y económicas; proporcionando un análisis crítico ante problemáticas que forman parte de la sociedad en la que vivimos. El artista vive inmerso en ese contexto y lo que en él ocurre le influye y determina para utilizar el arte como una manera de expresar acontecimientos o emociones, denunciar ciertos aspectos de la sociedad y hacer visible lo oculto.

\section{LA INFLUENCIA DE LOS CONTEXTOS EN EL ARTE}

Se aporta un significado del contexto entendido como ámbito temático que tiene un componente social dónde surgen las ideas para el artista. Distinguimos tres categorías que responden a los intereses del artista en torno a las problemáticas que plantean. Una primera categoría son los contextos culturales, sus obras nos hacen replantearnos estereotipos en torno a la enfermedad mental y reconsiderar la inclusión de otros espacios en el contexto hospitalario. Una segunda referida a los contextos políticos, en los que el arte sirve para entender, visibilizar una realidad difícil. Por último, los contextos económicos, relativos a la pobreza, inmigración y clases sociales que configuran escenarios diferenciados para la creación.

Una de las formas de entender un proyecto artístico es saber situarlo dentro de su contexto histórico, entendiéndolo más allá de los factores que envuelven a una obra y que la sitúan en una línea del tiempo (Richmond 2009). El acercamiento que propone implica una reflexión íntima del entorno del artista y el modo en cómo ese contexto le influencia en el proceso de creación. Se proponen tres lecturas para entender los vínculos que una obra mantiene con ese contexto. La primera establece una identificación entre cuestiones íntimas del artista y su obra. Una segunda, atiende a las circunstancias externas que envuelven al artista y que influencian sus pensamientos hacia la obra. Finalmente, identifica los aspectos del contexto social y cultural del artista presentes en la obra. Se trata de tres círculos de análisis de la creación partiendo de lo íntimo a lo general. Para entender la influencia que mantienen esos aspectos contextuales con cada proyecto proponemos tres lecturas:

1. Esfera personal: referida a las conexiones entre la obra y aspectos biográficos, del contexto familiar y vivencias del artista.

2. Ámbito social y cultural: aquellos aspectos culturales, sociales, políticos, económicos que se identifican en la obra y hablan al mismo tiempo del artista.

3. El proyecto: es una descripción de la obra que aporte significado atendiendo a cuestiones que son reflejo de las problemáticas que tratan. Se analiza las repercusiones del proyecto y los modos de cómo cada artista cuestiona problemas o situaciones que les preocupan y como buscan una respuesta.

\section{CONTEXTOS CULTURALES. EL HOSPITAL COMO ESPACIO PARA LA CREACIÓN}

Esta temática se centra en artistas que utilizan el hospital como espacio para la creación. Josep María Martín reflexiona sobre el espacio físico del hospital y plantea la creación de espacios no convencionales a partir de las necesidades de quienes lo habitan. Javier Téllez también se interesa por la idea del espacio físico, pero entendido como elemento externo que influye sobre las emociones de pacientes.

\subsection{JOSEP MARÍA MARTÍN - Prototipo de Espacio para gestionar emociones en el hospital}

Josep María Martín (Ceuta, 1961) vive y trabaja en Barcelona, profesor de arte en Pole Arts Actión, HEAD [Haute École d'Art et de Design] de la Universidad de Arte y Diseño en Ginebra y responsable Pedagógico en la L'École Superieur de Beaux-Art de Perpiñán. 
Su trabajo como profesor está vinculado con su obra, cada proyecto implica acciones pedagógicas con personas que son agentes activos de ese contexto en el que trabaja. Para el artista, la participación y colaboración de éstas es necesaria durante el proceso de creación, para entender puntos de vista, lecturas con las que generar la idea para una obra relevante para todos. La apertura del artista también se dirige hacia la colaboración con otros profesionales que mantienen una estrecha relación con ese espacio.

La elección del hospital como espacio para la creación ha sido protagonista en dos de sus obras, una en el Hospital Provincial de Castellón y otra, en el Hospital Saint-Jean Roussillon de Perpiñan.

En sus proyectos los espacios son entendidos como escenarios para la creación de una obra y punto de encuentro de debates en torno a un tema.

Prototipo de Espacio para Gestionar las Emociones fue un encargo que el Espacio de Arte Contemporáneo de Castellón hizo al artista para el Hospital Provincial de Castellón, a partir del proyecto realizado en el Hospital de Perpiñan. El artista realizo entrevistas a personas implicadas como el director, el personal sanitario, los enfermos y familiares. La entrevista es un acercamiento íntimo para conectar con las personas y comprender sus sentimientos sobre las relaciones con ese espacio. Así se detecta la necesidad de generar un espacio para gestionar las emociones equipado para actividades que sean una ayuda especializada en la superación de situaciones con gran carga emocional como, por ejemplo, la enfermedad y la muerte.

\subsection{JAVIER TELLEZ - El rinoceronte de Durero -}

Javier Téllez (Venezuela, 1969). Artista interesado en la enfermedad mental y en el cine como medio expresivo. Ambos elementos están presentes en su obra por la calidad estética y conceptual que contienen. Sus padres psiquiatras de profesión le hicieron mantener una relación natural con este tipo de instituciones desde su infancia.

Su obra contribuye a repensar los estereotipos que la sociedad ha etiquetado a determinados colectivos, por un tipo de discapacidad o de enfermedad mental. La película da visibilidad a estos enfermos y los dignifica.

En O Rinoceronte de Durero (2010) Téllez escogió como escenario el panóptico del Hospital Miguel Bombarda de Lisboa. Es una construcción diseñada por Jeremy Bentham en el siglo XVIII para que el vigilante situado en una torre central tuviera una completa visibilidad de los que habitan ese espacio. Este tipo de arquitectura ha sido utilizada para la vigilancia de presos en instituciones penitenciarias como de enfermos mentales en psiquiátricos.

Para Téllez existe una relación entre enfermedad mental y arquitectura, ya que el internamiento siempre se realiza en espacios de aislamiento. "La institución psiquiátrica es para el paciente una casa forzada, una camisa de fuerza arquitectónica en la que éste debe sobrevivir, o la cual debe transgredir" (Reyes, 2010). La elección del panóptico es como contexto en el que los pacientes imaginan vivir en un confinamiento extremo, en el que cada celda representa el aislamiento que la enfermedad les genera, mientras la presencia intermitente de un rinoceronte gira alrededor del patio. El animal guarda una clara alusión a la propia historia de Portugal y el grabado del Rinoceronte de Alberto Durero.

El Rinoceronte de Durero (2010) fue realizado con enfermos mentales y en colaboración con instituciones psiquiátricas de Portugal. El proyecto comienza con un contacto con los pacientes en el que el artista les invita a trabajar en un proyecto conjunto. Los pacientes pasan de espectadores a creadores y actores de una película, en la que adoptan el papel de los habitantes de las celdas de ese panóptico, mientras que un rinoceronte disecado gira en el espacio exterior. Los pacientes experimentan la sensación de reclusión, mientras leen fragmentos de la cueva de Platón, cartas de Jeremy Bentham que aluden a las sensaciones sobre el internamiento. El rinoceronte asombra a los enfermos, metáfora de cómo la sociedad actúa ante algo tan desconocido como es la enfermedad mental. La obra toma como título el grabado de Durero, para recordarnos que la imagen de la enfermedad mental es todavía desconocida, como lo fue el rinoceronte en el siglo XVI.

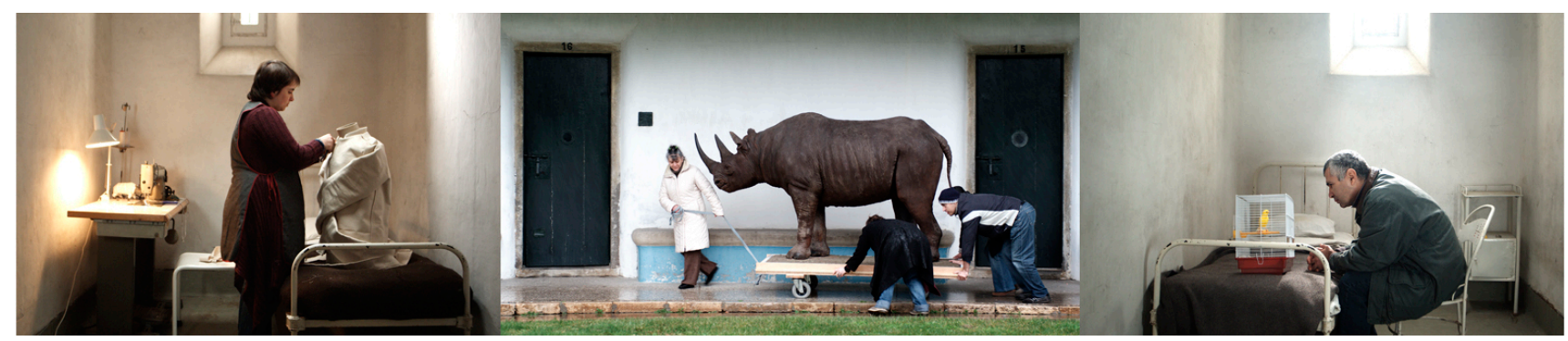

Ilustración 1. Fotocomposición escenas de $O$ rinoceronte de Dürer (2010), de Javier Téllez. Cortesía de Galerie Peter Kilchmann 


\section{CONTEXTOS POLITICOS}

Esta temática referida a dos artistas que se involucran en contextos concretos que dialogan sobre las consecuencias que experimentan las personas que viven en territorios inciertos y en los que su bienestar está supeditado a decisiones políticas. Mariana Cabello realiza un proyecto sobre cómo influye la situación política en el imaginario cubano. Wendy Ewald colabora con la comunidad de refugiados de Margate, en especial con niños que viven y experimentan la incertidumbre de tener un hogar.

\subsection{MARIANA CABELLO - Light Habana}

María Cabello (México, 1985). Realizó sus estudios de Arquitectura en México. En el 2012 realiza un Master en Bellas Artes en Diseño en la Universidad de Konstfack (Suiza) y desarrolla sus estudios de doctorado en la Universidad de Porto (Portugal).

Su obra muestra interés por la creación de espacios ficticios, construcciones que te trasladan a una realidad inventada y que conecta con sensaciones colectivas al sumergirse en un espacio que aleje al individuo de la realidad. En Light Habana (2013) las instalaciones son apropiaciones del imaginario construido en las obras de ciencia ficción de artistas cubanos.

Con la legalización del comercio privado en Cuba en 2010, surgen iniciativas privadas que tratan de regenerar sus ciudades. Para la artista resulta necesaria la inmersión en el contexto de la isla, para comprender la repercusión que tiene el cambio en la sociedad cubana. El punto de partida, fue la elección de obras de ciencia ficción para comprender el pensamiento de los cubanos y los deseos de cambio reflejado en su estilo de vida. Construye instalaciones a partir de la interpretación que hace de los textos leídos y selecciona lugares específicos de la ciudad como espacios expositivos y para un encuentro sitiado con los artistas.

Light Habana (2013) es una investigación realizada en La Habana a partir de obras literarias de ciencia ficción de artistas cubanos. Consta de varias fases. Primero hay una selección del material para la creación artística, luego la creación de instalaciones a partir de la interpretación de las obras y finalmente las entrevistas situadas entre cada escritor y la artista, un diálogo para la interpretación compartida de obras. Las entrevistas son parte clave del proceso porque es una forma de intercambiar impresiones sobre obras expresadas en lenguajes diferentes y que conjuntamente extraen la percepción popular de la realidad política de la isla.
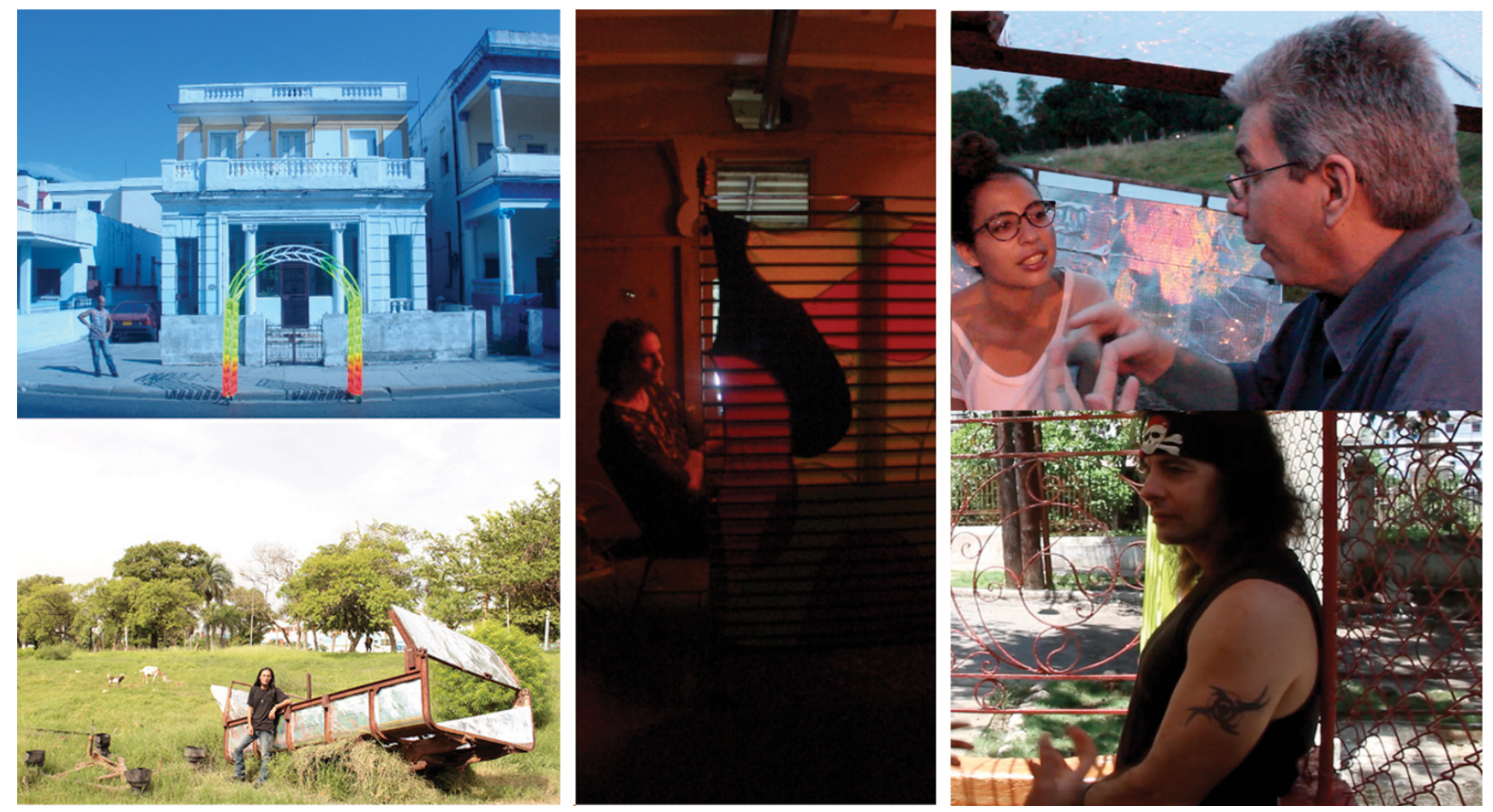

Ilustración 2. Fotocomposición de imágenes de las instalaciones y conversaciones de Light Habana (2010), de Mariana Cabello. Cortesía de la artista. 


\subsection{WENDY EWALD - Towards a Promise land}

Wendy Ewald (EEUU, 1951) lleva más de cuarenta años desarrollando proyectos colaborativos a través de la fotografía con diferentes comunidades alrededor del mundo. Ha obtenido ayudas como MacArthur, Fulbright y de la Fundación Andy Warhol entre otros reconocimientos. Actualmente es artista en residencia en la Universidad de Amherst, Massachusetts.

A menudo, los protagonistas de sus proyectos son niños y adolescentes que viven en contextos desfavorecidos y que se enfrentan a situaciones políticas críticas. Las imágenes resultan una vía accesible para expresar su identidad y entender críticamente su presente. Existe un programa de carácter más formal Alfabetización a través de la fotografía [Literacy through Photography -LTP] que se implementó en las escuelas de Durham durante más de veinte años. El programa LTP pretende introducir la fotografía como una vía para la enseñanza de la lectura y escritura (Peña, 2011).

Towards a Promised Land (2004-2006) es un proyecto realizado con niños residentes en la ciudad británica de Margate. Esta localidad es residencia de muchas familias de refugiados o en espera de conseguir el asilo político en el país. Un primer paso fue enseñarles el manejo de las cámaras Polaroid mientras que Ewald realizó retratos de cada uno. Después les pidió a los niños fotografiar objetos que hubieran traído consigo por su valor emocional al trasladarse a vivir a Margate. Paralelamente fotografiaron su entorno, sus familias, dibujaron mapas y escribieron sobre las imágenes.

Finalmente las imágenes, impresas en grandes pancartas, fueron expuestas en negocios locales de la ciudad mostrando a los niños como protagonistas en un entorno que los invisibiliza. "La gente que se traslada a Margate suele pasar desapercibida para los que allí viven. Darles visibilidad de un modo tan monumental era una idea interesante y provocadora" Ewald (2006, p.146).

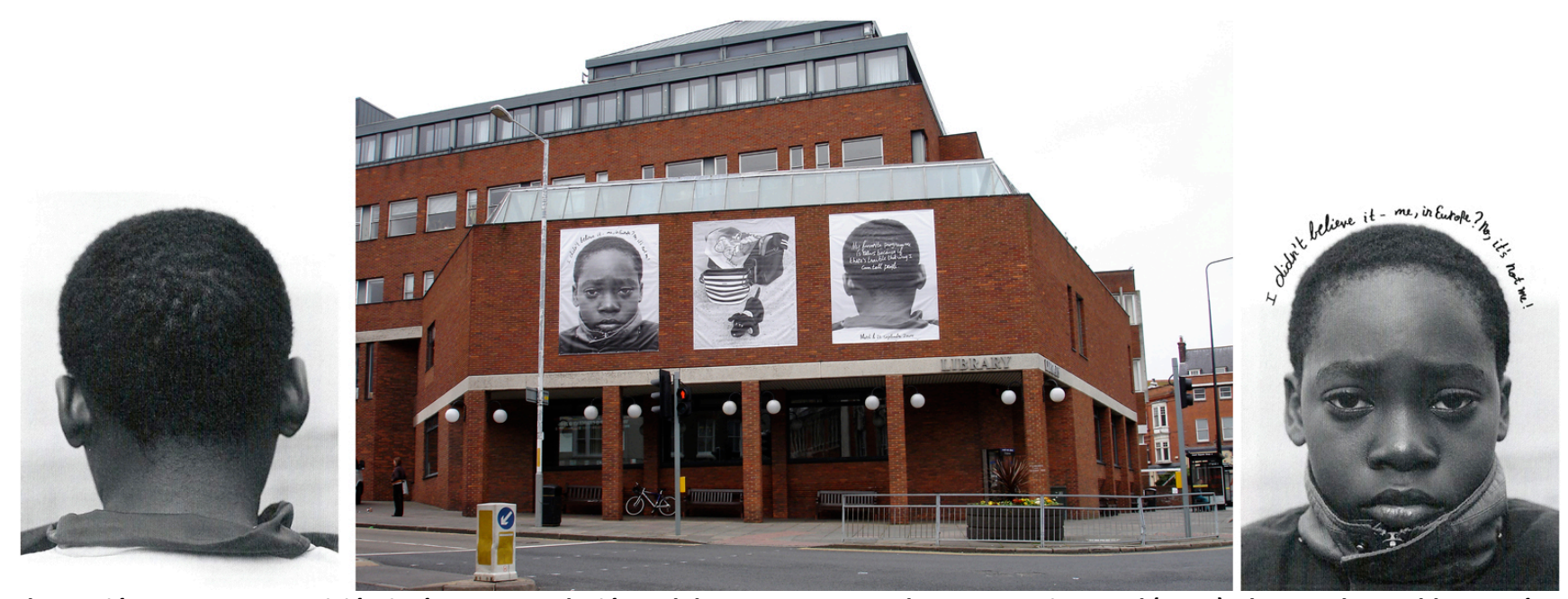

Ilustración 3. Fotocomposición imágenes Instalación y del proyecto Towards to a promise Land (2006), de Wendy Ewald.Cortesía de la artista.

\section{CONTEXTOS ECONÓMICOS}

Temática vinculada a la pobreza desde dos miradas. Una de ellas es el proyecto Luz Nas Vielas que busca empoderar a los miembros de la comunidad haciéndoles partícipes de una intervención urbana en las Favelas de Brasil. Otra llamada Salitre que muestra la crudeza de vivir una realidad, como es la que varios senegaleses experimentan al vivir en una casa patera.

\subsection{BOA MISTURA - LUz Nas vielas -}

Colectivo de artistas creado en 2001 procedentes de distintas disciplinas y que mantienen un interés común por el grafiti. Su trabajo toma como escenario el espacio público y su trabajo es reconocido por las intervenciones urbanas que generalmente persiguen la inclusión social. En los procesos de cada proyecto se combinan la pintura, el diseño y el juego. Consideran su trabajo como algo que genera vínculos entre las personas de las ciudades, para hacerlas más cooperativas y solidarias.

Luz Nas Vielas (2012) se desarrolla en zonas marginales de la Favela de Vila Brasilandia, São Paulo. Los creadores convivieron en una favela con una familia, conociendo así la realidad y su contexto social. Boa Mistura entendió que las calles no eran solo zonas de paso sino que conectaban la parte alta con la baja y eran conocidas como "vielas" o callejuelas. El trabajo expresa la complejidad de la zona, aplana la perspectiva desde un punto mediante el anamorfismo; si el espectador se sitúa en un lugar específico se leen palabras como: belleza, amor, dulzura Y orgullo que empoderan a las personas y convierten a la favela en espacio de comunicación y tránsito. 


\subsection{JUAN VALBUENA -Salitre -}

Juan Valbuena (Madrid, 1973). Fotógrafo fundador del grupo NOPHOTO, coordinador de PROYECTA, una iniciativa que utiliza la proyección como forma de difusión de trabajos de jóvenes autores y es director editorial de PHREE. Sus iniciativas artísticas tienen como temática el viaje y la memoria en relación entre el ser humano, la fotografía y el territorio.

En su obra Salitre trata de hacer visible como viven los senegaleses en Madrid en una Casa patera. Sensible al contexto que se viven estas comunidades invisibles para el resto de la sociedad y mostrarlo con imágenes de sus lugares de origen, así como fotografías. Su interés es utilizar la fotografía como medio para expresar de una forma artística ámbitos desfavorecidos.

Salitre (2009-2012) con senegaleses que viven en Madrid en una casa patera. El proyecto se compone de una caja con trece libros: doce realizados por cada uno de los habitantes de la casa con fotografías, dibujos, carnets, pasaportes, etc. El último con imágenes que el artista realizó en la casa: escenas, retratos, cartas, objetos de la vida cotidiana, hasta que fueron desalojados.

\section{FUENTES REFERENCIALES}

BLANCO, P. [et al](eds.)2001. Modos de hacer. Arte crítico, esfera pública y acción directa. Salamanca: Ediciones Universidad de Salamanca. ISBN 84-7800-892-6.

CABELLO, M. [sitio web]. 2015. Light Habana [Consulta: 05-05-2015]. Disponible en http://www.marianacabello.com/Light-Habana

LANGER, S. K. 1966. Los problemas del arte. Diez conferencias filosóficas. Buenos Aires: Infinito.

MARTín, J. M. [sitio web]. 2010. Prototipo de espacio para gestionar las emociones en el hospital. [Consulta 20-04-2015]. Disponible en http://www.josep-mariamartin.org/es/Prototipo-gestionar-emociones/index.php

PEÑA, N. 2011. Entrevista a Wendy Ewald. ¿Cómo enseñar propuestas colaborativas a través de la fotografía? Pulso, 34, 211-223. ISSN 1577-0338.

PETER KILCHMANN [sitio web]. 2015. O Rinoceronte de Dürer [Consulta: 05-05-2015]. Disponible en http://www.peterkilchmann.com/artists/overview/++/name/javier-t\%25C3\%25A9llez/id/24/media/_dsc7602.jpg/

REYES, P. 2010. Interview Javier Téllez by Pedro Reyes. Bomb [en línea], 110 (1) [Consulta: 10-04-2015]. Disponible en http://bombmagazine.org/issues/110

RICHMOND, W. 2009. Art without compromise*. Nueva York: Allworth Press. ISBN 978-1-58115-666-9.

VALBUENA, J. [sitio web]. Proyecto Salitre. No photo [Consulta: 05-05-2015]. Disponible en http://nophoto.org/salitre 